\title{
Food Access and Perceptions of the Community and Household Food Environment as Correlates of Fruit and Vegetable Intake among Rural Seniors
}

\author{
Joseph R Sharkey*1,2, Cassandra M Johnson¹ and Wesley R Dean¹
}

\begin{abstract}
Background: Although the importance of fruit and vegetable consumption to health has been well established, few studies have focused on access to fruits and vegetables in rural areas; even fewer examined the relationship between food access and fruit and vegetable consumption among seniors.

Methods: To examine the spatial challenges to good nutrition faced by seniors who reside in rural areas and how spatial access influences fruit and vegetable intake.

A cross-sectional analysis using data from the 2006 Brazos Valley Health Assessment (mailsurvey) for 582 rural seniors (60-90 years), who were recruited by random digit dialing; food store data from the 2006-2007 Brazos Valley Food Environment Project that used ground-truthed methods to identify, geocode, and inventory fruit and vegetables in all food stores.

Results: Few of the BVHA seniors consumed the recommended intakes of fruits or vegetables; women consumed more servings of fruit ( $1.49 \pm 0.05$ vs. $1.29 \pm 0.07, p=0.02)$, similar servings of vegetables $(2.18 \pm 0.04$ vs. $2.09 \pm 0.07, p=$ 0.28 ), and more combined fruit and vegetables ( $3.67 \pm 0.08 \mathrm{vs} .3 .38 \pm 0.12, p=0.04)$ than men. The median distances to fresh fruit and vegetables were 5.5 miles and 6.4 miles, respectively. When canned and frozen fruit and vegetables were included in the measurement of overall fruit or vegetables, the median distance for a good selection of fruit or vegetables decreased to 3.4 miles for overall fruit and 3.2 miles for overall vegetables. Almost $14 \%$ reported that food supplies did not last and there was not enough money to buy more. Our analyses revealed that objective and perceived measures of food store access - increased distance to the nearest supermarket, food store with a good variety of fresh and processed fruit, or food store with a good variety of fresh and processed vegetables - were associated with decreased daily consumption of fruit, vegetables, and combined fruit and vegetables, after controlling for the influence of individual characteristics and perceptions of community and home food resources.
\end{abstract}

Conclusions: Findings suggest that interventions designed to increase fruit and vegetable consumption among rural seniors should consider strategies to ameliorate differential access to healthy food due to food store distance.

\section{Background}

The percentage of older adults with nutrition-related health conditions, such as obesity, diabetes, cardiovascular disease, and some cancers has been increasing [1]. Healthy eating, such as the consumption of fruit and vegetables is now recognized as one modifiable determinant for the prevention and management of chronic health

*Correspondence: jrsharkey@srph.tamhsc.edu

1 Program for Research in Nutrition and Health Disparities, School of Rural Public Health, Texas A\&M Health Science Center, MS 1266, College Station, TX 77843-1266, USA

Full list of author information is available at the end of the article conditions; and is targeted in national recommendations [2-7]. However, the current focus on fruit and vegetables is limited to fresh fruit and vegetables [8-17], which ignores dietary recommendations and the nutrient benefits of canned and frozen fruit and vegetables $[3,18]$.

Personal and environmental characteristics result in differential access to health resources and serve as either barriers or enhancements to healthy eating, especially in rural areas $[19,20]$. Without access to a supermarket, vulnerable populations like older adults may struggle to obtain the food needed for a healthy diet and face an 
increased risk of diet-related chronic disease [21-23]. Previous studies have examined personal or individual factors such as gender, income, and education and how these factors affect health and nutrition [24-26], while more recent studies have considered the effect of aspects of the built environment on diet [9,27-31]. Urban populations have been the primary target for this latter research focused on identifying environmental barriers to healthy eating in the U.S. [32-36] and elsewhere [37-43]. However, few studies examined food access and shopping among older adults [44-46]. Further, only a limited number of studies focused on environmental factors and their influence on access to food among rural populations [4753], and none were found examining environmental barriers to healthy foods among older adults in rural areas.

Physical access is a major problem for people without cars, the elderly, people on low incomes, and residents in rural areas $[51,54]$. There is strong evidence that residents of rural areas are affected by poor access to supermarkets and healthy foods [49-51,55-58]. However, little is known about the spatial challenges to good nutrition faced by seniors who reside in rural areas and how spatial access influences fruit and vegetable intake. Nutritional disparities faced by rural seniors make understanding access to a variety of fruits and vegetables critical. The aims of this study are to (a) depict potential spatial access from rural neighborhoods to a mix of retail food stores that market fruit and/or vegetables; (b) describe individual and neighborhood characteristics, spatial access to food resources, and fruit and/or vegetable intake; and (c) examine the associations among individual and neighborhood characteristics, perceived and objective measures of food access, and fruit and/or vegetable intake of rural seniors. We hypothesized that rural seniors who reside at a greater distance from food stores would report lower fruit and/or vegetable intake.

\section{Methods}

\section{Sample and Study Design}

We used data from the 2006 Brazos Valley Health Assessment (BVHA), the 2006-2007 Brazos Valley Food Environment Project (BVFEP), and the decennial 2000 U.S. Census Summary File 3 (SF-3) for a 6-county rural area (see Figure 1). The rural study area included 101 census block groups (CBG), land area of approximately 4,500 square miles, and population of more than 119,650 people [51,59]. Regular public transportation services, such as fixed route, commuter, or taxi services, were not available in the study area $[60,61]$. Data for the BVHA were collected from 663 rural seniors (age $\geq 60$ years) who were recruited into a large community assessment through random digit dialing and follow-up mail survey; detailed methodology has been described elsewhere [62]. The analytic sample included rural seniors with residential

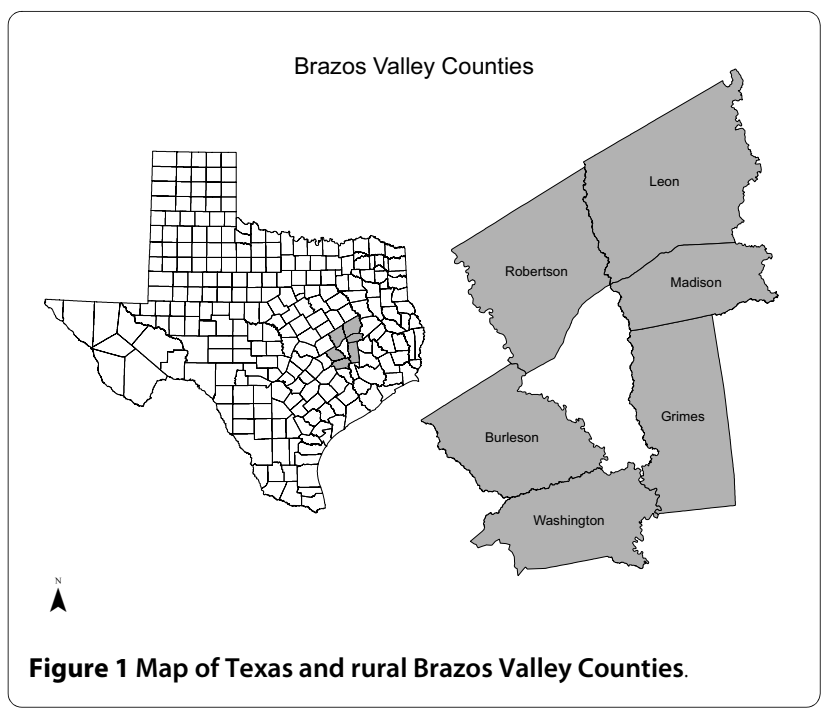

addresses and complete nutrition data $(n=582)$; all participants were geocoded to their residence. In the BVHA, respondents were asked about daily intakes of fruit and/ or vegetables, availability and perception of community retail food resources, household food resources, and demographic characteristics. The BVHA and BVFEP were approved by the Institutional Review Board at Texas A\&M University.

\section{Measures}

\section{Fruit and vegetable intake}

Fruit and vegetable intakes were separately measured by a validated, self-reported two-item screener $[63,64]$. One item asked participants to report the number of servings of fruit ( $1 / 2$ cup of fruit or $3 / 4$ cup fruit juice) usually consumed each day; the second item targeted the number of servings of vegetables ( $1 / 2$ cup cooked or 1 cup raw) consumed daily. In addition to separate intakes of fruit and vegetables, a combined fruit and vegetable intake variable was calculated as the total of both fruit and vegetable intakes. Community retail food resources. The perceived adequacy of community food resources was assessed using a 5-point Likert scale (e.g., $1=$ strongly agree to $5=$ strongly disagree) for three items about the local community: 1) little variety in types of foods that can be purchased; 2) few grocery stores or supermarkets; and 3) food prices are high. Responses were collapsed into binary variables, based on strongly agree/agree vs. other responses. Perceptions related to the store where most of the groceries were purchased were assessed on a 5-point Likert scale (e.g., 1 = excellent 5 = poor) using three questions: 1) how would you rate the variety of fruits and vegetables at this store; 2) how would you rate the freshness of fruits and vegetables; and 3) how would you rate the price of fruits and vegetables? Binary variables were constructed as fair/poor vs. all others. Household food 
resources. Adequacy of household food resources was assessed using three items. Two statements asked whether the following was often true, sometimes true, or never true in their household in the past month: 1) the food we bought last month didn't last and we didn't have enough money to buy more; and 2) we couldn't afford to eat balanced meals. Binary variables were constructed as often/sometimes true vs. never true. In the third question, participants were asked (yes or no) whether they and/or other adults in the household ever cut the size of meals or skipped meals in the last 12 months because there wasn't enough money to buy food.

Sociodemographic characteristics included age (range of 60-90 years), gender, race/ethnicity (all minority vs. nonHispanic white), household income $(\leq 100 \%$ Federal Poverty Level [FPL], 101\%-199\% FPL, and $\geq 200 \%$ FPL), years of education completed (low [< high school] vs. high [ $\geq$ high school graduate]), marital status (married vs. not married), and household composition (lives alone vs. lives with others).

\section{Objective measurement of fruit and vegetable availability}

BVFEP data included the on-site identification and geocoding of all supercenters, supermarkets, grocery stores, convenience stores, dollar stores, mass merchandisers, and pharmacies; and completion of an observational survey by trained researchers of the availability and variety of fresh and processed (canned, frozen, and juice) fruits and vegetables in the 185 food stores that marketed some form of fruit or vegetable $[51,55,65]$. The availability of fruit and vegetables was separately determined from the presence and variety of fresh and processed fruits and vegetables [55,65]. Processed fruit and vegetables included canned (in natural juice or in light syrup), frozen (without added sugar or sauce), and 100\% juice items [18]. Variety was defined as the number of different food items within a fruit or vegetable category (e.g., number of different fresh fruits). Based on overall fruit and vegetable scores, four variables were constructed for good availability of fresh fruit, fresh and processed fruit, fresh vegetables, and fresh and processed vegetables [65].

\section{Residential neighborhood measures}

Socioeconomic characteristics were extracted from the SF-3 for all 101 CBG in the rural study area to describe socioeconomic deprivation and population density [51]. Home addresses for all respondents were used to identify the neighborhood or CBG of residence. Based on the distribution of weighted socioeconomic deprivation scores, neighborhoods (CBG) were classified as being low, medium or high deprivation [51]. Population density was calculated as the number of persons $/ \mathrm{mi}^{2}$ in each CBG. Neighborhood deprivation and population density data were linked to each respondent through the residential CBG.

\section{Potential spatial access to fruit and vegetables}

Network distance was calculated with ESRI's Network Analysis extension in ArcInfo 9.2, which computed the distance along the road network to the geographic position measured in front of each food store. Separate network distances were calculated from the residential address of each BVHA senior respondent to the nearest corresponding supermarket, and food store (regardless of type) with a good selection of fresh fruit, fresh and processed fruit, fresh vegetables, or fresh and processed vegetables. The network distance to the nearest food store was calculated between paired point data (respondent address and nearest corresponding food store within the study area).

\section{Statistical analyses}

Release 11 of Stata Statistical Software was used for all statistical analyses; $p<0.05$ was considered statistically significant. Descriptive statistics were estimated for sociodemographic characteristics; residential neighborhood; fruit and vegetable intake; distances from residence of each respondent to the nearest supermarket and nearest food store (regardless of type) that offered a good selection of fresh fruit, fresh and processed fruit, fresh vegetables, or fresh and processed vegetables; and community and household food resources. A 2-phase approach was used to examine the association of sociodemographic and neighborhood characteristics with fruit and/or vegetable intake. First, bivariate correlations between fruit and/or vegetable intake and sociodemographic characteristics, residential neighborhood, community retail food resources, and household food resources were estimated using Pearson's productmoment correlation. Second, multivariable linear regression models were individually fitted using backward elimination strategy to determine the relationship of sociodemographic characteristics, community and household food resources, and network distance to food stores with fruit and/or vegetable intake. Variables that were associated with fruit and/or vegetable intake $(p<$ $0.10)$ were included in the multivariable models. Separate models were estimated for three outcome variables, with robust (White-corrected) SEs for heteroscedasticity of unknown form: fruit intake, vegetable intake, and combined fruit and vegetable intake. In model 1, all candidate variables from the bivariate analyses were simultaneously entered, with backward elimination of variables not statistically significant $(p<0.05)$. Network distance to the nearest supermarket was added as an explanatory term. In model 2, distance to nearest supermarket was replaced with distance to the nearest food store with a good selection of fresh fruit or vegetables. In model 3, network distance to the nearest food store with a good selection of fresh and processed fruit or vegetables replaced distance 
to the nearest food store with a good selection of fresh fruit or vegetables $s$ in model 2.

\section{Results}

Sample and neighborhood characteristics

Sample characteristics between the analytic sample of 582 seniors who completed all nutrition-related questions in the BVHA and the 663 rural seniors who returned surveys were not significantly different (data not shown). The mean age for the 582 BVHA respondents was almost 70 years; $68 \%$ were women; almost $65 \%$ were married; and $27 \%$ lived alone (Table 1). More than $33 \%$ of the seniors reported a household income below $200 \%$ of the Federal Poverty Level; women were more likely to report a poverty level income than men $(20.4 \%$ vs. $9.1 \%, p$ $<0.001)$, as well as older seniors $(p<0.001)$. Almost one-

Table 1: Characteristics of Rural Seniors in 2006 Brazos Valley Health Assessment ( $\mathbf{n}=\mathbf{5 8 2}$ )

\begin{tabular}{|c|c|c|}
\hline & $\%(n)$ & Mean \pm SD \\
\hline \multicolumn{3}{|l|}{ Individual characteristics } \\
\hline Age, y & & $69.92 \pm 6.91$ \\
\hline Women & $68.2(397)$ & \\
\hline \multicolumn{3}{|l|}{ Race/ethnicity } \\
\hline Minority & $14.4(84)$ & \\
\hline \multicolumn{3}{|l|}{ Household income } \\
\hline$\leq 100 \% \mathrm{FPL}$ & $17.0(99)$ & \\
\hline $101-199 \% \mathrm{FPL}$ & $16.3(95)$ & \\
\hline \multicolumn{3}{|l|}{ Education } \\
\hline Low (< High school) & $13.1(76)$ & \\
\hline \multicolumn{3}{|l|}{ Marital status } \\
\hline Married & $64.8(377)$ & \\
\hline \multicolumn{3}{|l|}{ Household composition } \\
\hline Lives alone & $27.7(161)$ & \\
\hline \multicolumn{3}{|l|}{ Residential Neighborhood } \\
\hline \multicolumn{3}{|l|}{ Deprivation, \% (n) } \\
\hline Low & $29.6(172)$ & \\
\hline Medium & $46.2(269)$ & \\
\hline High & $24.2(141)$ & \\
\hline \multicolumn{3}{|l|}{ Population density (persons/mi²) } \\
\hline Low $(<14)$ & $27.0(157)$ & \\
\hline Medium (14-127) & $46.6(271)$ & \\
\hline High (>127) & $26.5(154)$ & \\
\hline \multicolumn{3}{|l|}{ Daily dietary intakes } \\
\hline Fruit & & $1.43 \pm 0.98$ \\
\hline Vegetables & & $2.15 \pm 0.91$ \\
\hline Combined fruit and vegetables & & $3.58 \pm 1.60$ \\
\hline
\end{tabular}

$\mathrm{SD}=$ standard deviation fourth of respondents resided in a high deprivation neighborhood; the neighborhood population density was less than 14 persons $/ \mathrm{mi}^{2}$ for $27 \%$ of respondents. Few of the BVHA seniors consumed the recommended intakes of fruits or vegetables; women consumed more servings of fruit ( $1.49 \pm 0.05$ vs. $1.29 \pm 0.07, p=0.02)$, similar servings of vegetables ( $2.18 \pm 0.04$ vs. $2.09 \pm 0.07, p=0.28)$, and more combined fruit and vegetables $(3.67 \pm 0.08$ vs. $3.38 \pm 0.12, p=0.04$ ) than men.

\section{Objective measures of potential food access}

The rural food environment consisted of 186 food stores, including one supercenter, 11 supermarkets, 12 grocery stores, 141 convenience stores, 16 dollar stores, four mass merchandisers, and one pharmacy [51]. Fruit and vegetable data were collected in 185 food stores; one convenience store was excluded because of refusal for an instore survey of food items [65]. Using network distance measures from each participant's residence to the nearest supermarket, the median distance was 8.7 miles (Table 2). Food stores, regardless of type, with a good selection of fresh and processed fruit and vegetables were identified from in-store food surveys [55]. The median distances to fresh fruit $(5.5$ miles $)$ and fresh vegetables $(6.4$ miles $)$ were greater than median distances to the nearest store with a good selection of fresh and processed fruit (3.4 miles) or vegetables (3.2 miles).

\section{Perceived measures of community and household food resources}

Individual evaluations of community food resources, stores where most of the groceries are purchased, and household food resources are presented in Table 3 . Seniors believed community food resources were limited in variety of foods that can be purchased (32\%), presence of few stores or supermarkets (59.6\%), and high food prices (79.5\%). Participants identified concerns with vari-

Table 2: Potential spatial access (in miles) from rural senior's residence to the nearest supermarket and good selection of fruit and vegetables $(n=582)$

\begin{tabular}{|c|c|c|c|}
\hline & Mean (SD) ${ }^{a}$ & Median & IQR $^{\mathbf{b}}$ \\
\hline Supermarket & $9.9(9.2)$ & 8.7 & $1.06-14.46$ \\
\hline \multicolumn{4}{|l|}{ Fresh } \\
\hline Fruit & $6.1(5.3)$ & 5.5 & $0.87-9.65$ \\
\hline Vegetables & $6.7(5.7)$ & 6.4 & $0.97-10.47$ \\
\hline \multicolumn{4}{|c|}{ Fresh and processedc } \\
\hline Fruit & $4.4(4.1)$ & 3.4 & $0.58-7.62$ \\
\hline Vegetables & $4.2(4.0)$ & 3.2 & $0.65-6.89$ \\
\hline
\end{tabular}


Table 3: Perceptions of Rural Seniors on Adequacy of Community and Household Food Resources $(n=582)$

$\%(n)$

\section{Community food resources}

Little variety of foods that can be purchased

$32.0(186)$

Few grocery stores or supermarkets

59.6 (347)

Food prices are high

$79.5(463)$

Food store where most groceries purchased

Variety of fruits and vegetables is fair/poor

$10.0(58)$

Freshness of fruits and vegetables is fair/ poor

Price of fruits and vegetables is fair/poor

\section{Household food resources}

Food bought last month didn't last and we didn't have enough money to buy more

In the last month, we couldn't afford to eat balanced meals

In the past 12 months, we had to cut size of our meals or skip meals because there wasn't enough money to buy food resources, and network distance to food stores with daily fruit and vegetable intake among rural seniors.

Lower fruit intake (Table 4) among rural seniors was associated with living a greater distance to the nearest supermarket or food store with a good selection of fresh and processed fruit, controlling for individual characteristics and food resources. A 0.012 decrease in daily servings of fruit was observed for each mile to the nearest supermarket and 0.027 decrease for each mile to the nearest store with a good selection of fresh and processed fruit. Regardless of model, participants who resided in households where food purchased in the previous month did not last or who shopped in food stores where they considered the variety of fruits and vegetables as fair or poor consumed fewer servings of fruit. Increased age and female gender were associated with increased intake.

Lower vegetable intake (Table 5) was associated with living a greater distance from the nearest supermarket (0.008 decrease in daily servings of vegetables for each mile to the nearest supermarket); neither distance to nearest food store with a good selection of fresh vegetables nor good selection of fresh and processed vegetables was significantly correlated with vegetable intake. Lower vegetable intake was associated with food not lasting in the previous month, belief there were few grocery stores or supermarkets in their community, and living alone. Tables 6, 7 show the association of individual characteristics, food resources, and distance to food stores with combined intake of fruit and vegetables. As shown in table 6 and 7, increased distance to the nearest supermarket, increased distance to the nearest food store with a good variety of fresh and processed fruit, or increased distance to the nearest food store with a good selection of fresh and processed vegetables were associated with lower intake of combined fruit and vegetables. Each mile in distance to a supermarket was associated with a 0.02 reduction in daily servings; and each mile to fresh and processed fruit or vegetables was associated with 0.043 and 0.046 reduction in daily servings of fruit and vegetables. In addition, decreased number of combined servings was associated with living alone, food not lasting, and believing that there were few grocery stores or supermarkets in the community or that the variety of fruits and vegetables was fair or poor. Increased age and being female were associated with increased intake.

\section{Discussion}

The importance of fruit and vegetable consumption to health has been well established [7,66-68]. Considering the importance of geographic access to retail food resources, few studies have focused on access to fruit and vegetables in rural areas $[16,50,65]$; even fewer examined the relationship between food access and fruit and vegevidual characteristics, community and household food 
Table 4: Association of sample characteristics, community and household food resources, and network distance to food stores with fruit intake among 582 rural seniors, using multivariable linear regression models

\begin{tabular}{|c|c|c|c|c|c|c|}
\hline & \multicolumn{2}{|c|}{ Model: Supermarket } & \multicolumn{2}{|c|}{ Model 2: Fresh Fruit } & \multicolumn{2}{|c|}{$\begin{array}{l}\text { Model 3: Fresh and } \\
\text { Processed Fruit }\end{array}$} \\
\hline & Coef (SE) & $P$ & Coef (SE) ${ }^{a}$ & $P$ & Coef (SE) ${ }^{a}$ & $P$ \\
\hline \multicolumn{7}{|l|}{ Individual characteristics } \\
\hline Live alone & $-0.171(0.087)$ & 0.050 & $-0.158(0.087)$ & 0.070 & $-0.170(0.087)$ & 0.051 \\
\hline Female & $0.288(0.084)$ & 0.001 & $0.301(0.084)$ & 0.000 & $0.285(0.084)$ & 0.001 \\
\hline Age, $y$ & $0.028(0.006)$ & 0.000 & $0.028(0.006)$ & 0.000 & $0.029(0.006)$ & 0.000 \\
\hline \multicolumn{7}{|l|}{ Food Resources } \\
\hline Food not last & $-0.473(0.108)$ & 0.000 & $-0.464(0.109)$ & 0.000 & $-0.460(0.108)$ & 0.000 \\
\hline Few grocery stores & $-0.073(0.082)$ & 0.371 & $-0.093(0.081)$ & 0.253 & $-0.098(0.081)$ & 0.227 \\
\hline Fruit/vegetable variety & $-0.270(0.112)$ & 0.016 & $-0.281(0.112)$ & 0.012 & $-0.276(0.110)$ & 0.012 \\
\hline \multicolumn{7}{|l|}{ Distance to nearest food store } \\
\hline Supermarket ${ }^{b}$ & $-0.012(0.004)$ & 0.003 & & & & \\
\hline Fresh fruitc & & & $-0.013(0.007)$ & 0.067 & & \\
\hline Fresh and processed fruit ${ }^{d}$ & & & & & $-0.027(0.009)$ & 0.003 \\
\hline $\mathrm{R}^{2}$ & 0.111 & & 0.105 & & 0.112 & \\
\hline$P$ & $<0.0001$ & & $<0.0001$ & & $<0.0001$ & \\
\hline $\begin{array}{l}\text { a SE }=\text { White-corrected standard } \\
\text { b Network distance in miles from } \\
\text { c Network distance in miles from } \\
\text { d Network distance in miles from } \\
\text { and } 100 \% \text { juice) fruit }\end{array}$ & $\begin{array}{l}\text { cipant's residence t } \\
\text { cipant's residence t } \\
\text { cipant's residence t }\end{array}$ & $\begin{array}{l}\text { earest s } \\
\text { earest } f \\
\text { earest } f\end{array}$ & $\begin{array}{l}\text { narket } \\
\text { ore with a good sele } \\
\text { ore with a good sele }\end{array}$ & $\begin{array}{l}\text { ion of } f \\
\text { ion of } f\end{array}$ & $\begin{array}{l}\text { it } \\
\text { d processed (canne }\end{array}$ & rozen, \\
\hline
\end{tabular}

table consumption among seniors, regardless of location [44]. This study extends our understanding of spatial challenges to nutritional health faced by seniors in a large rural area lacking public transportation. This is the first study, to our knowledge, that examines the relationship between spatial access to food stores, especially food stores providing a good variety of fresh and processed (canned, frozen, and 100\% juice) fruit and vegetables, and daily intake of fruit, vegetables, and combined fruit and vegetables among rural seniors. Our analyses revealed that increased distance to the nearest supermarket, food store with a good variety of fresh and processed fruit, or food store with a good variety of fresh and processed vegetables was associated with decreased daily consumption of fruit, vegetables, and combined fruit and vegetables, after controlling for the influence of individual characteristics and perceptions of community and home food resources. The findings suggest that interventions designed to increase fruit and vegetable consumption among rural seniors should consider strategies to ameliorate differential access to healthy food due to food store distance. The implications of the findings regarding distance measures, however, should be tempered with the magnitude of the regression coefficients. For participants at the $75^{\text {th }}$ percentile for distance to the nearest supermarket, distance was associated with less than one-fifth serving of fruit, one-tenth of a serving of vegetables, and more than one-fourth of a serving of combined fruit and vegetables. At the same percentile for distance to the nearest food store with a good selection of fresh and processed fruit, this equated to one-fifth of a serving of combined fruit and vegetables. This equated to almost onethird of a serving for the $75^{\text {th }}$ percentile of distance to the nearest food store with a good selection of fresh and processed vegetables.

Although the food environment experienced by rural seniors is different from the food environment experienced by seniors in high-population-density urban and suburban areas [53], this study found a similar negative influence on fruit and vegetable consumption by retail store distance as that reported among 257 seniors in Brooklyn, NY [44]. There were some noticeable differences between the NY sample and our rural sample. First, the mean intake of combined fruit and vegetables was lower among the present study of rural seniors (3.58 in the rural sample compared with approximately 5 servings 
Table 5: Association of sample characteristics, community and household food resources, and network distance to food stores with vegetable intake among 582 rural seniors, using multivariable linear regression models

\begin{tabular}{|c|c|c|c|c|c|c|}
\hline & \multicolumn{2}{|c|}{ Model 1: Supermarket } & \multicolumn{2}{|c|}{ Model 2: Fresh Vegetables } & \multicolumn{2}{|c|}{$\begin{array}{l}\text { Model 3: Fresh and } \\
\text { Processed Vegetables }\end{array}$} \\
\hline & Coef (SE) ${ }^{a}$ & $\boldsymbol{P}$ & Coef (SE) a & $\boldsymbol{P}$ & Coef (SE) ${ }^{a}$ & $\boldsymbol{P}$ \\
\hline \multicolumn{7}{|l|}{ Individual characteristics } \\
\hline Live alone & $-0.373(0.086)$ & 0.000 & $-0.362(0.086)$ & 0.000 & $-0.370(0.086)$ & 0.000 \\
\hline Female & $0.206(0.082)$ & 0.013 & $0.217(0.082)$ & 0.008 & $0.210(0.082)$ & 0.011 \\
\hline Age, y & $0.017(0.005)$ & 0.003 & $0.016(0.005)$ & 0.003 & $0.017(0.005)$ & 0.002 \\
\hline \multicolumn{7}{|l|}{ Food Resources } \\
\hline Food not last & $-0.495(0.112)$ & $0.000)$ & $-0.486(0.113)$ & 0.000 & $-0.485(0.113)$ & 0.000 \\
\hline Few grocery stores & $-0.226(0.077)$ & 0.004 & $-0.242(0.077)$ & 0.002 & $-0.240(0.077)$ & 0.002 \\
\hline Fruit/vegetable variety & $0.128(0.119)$ & 0.281 & $-0.134(0.119)$ & 0.261 & $0.133(0.119)$ & 0.262 \\
\hline \multicolumn{7}{|l|}{ Distance to nearest food store } \\
\hline Supermarket ${ }^{\mathrm{b}}$ & $-0.008(0.004)$ & 0.033 & & & & \\
\hline Fresh vegetablesc & & & $-0.007(0.006)$ & 0.267 & & \\
\hline Fresh and processed vegetablesd & & & & & $-0.015(0.009)$ & 0.116 \\
\hline $\mathrm{R}^{2}$ & \multicolumn{2}{|l|}{0.125} & \multicolumn{2}{|l|}{0.119} & \multicolumn{2}{|l|}{0.121} \\
\hline$P$ & \multicolumn{2}{|l|}{$<0.0001$} & \multicolumn{2}{|l|}{$<0.0001$} & \multicolumn{2}{|l|}{$<0.0001$} \\
\hline $\begin{array}{l}\text { a SE }=\text { White-corrected standard errors } \\
\text { b Network distance in miles from partic } \\
\text { c Network distance in miles from partic } \\
\text { d Network distance in miles from partic } \\
\text { and } 100 \% \text { juice) vegetables }\end{array}$ & $\begin{array}{l}\text { int's residence to ne } \\
\text { nt's residence to ne } \\
\text { nt's residence to ne }\end{array}$ & $\begin{array}{l}\text { est sup } \\
\text { est foo } \\
\text { est foo }\end{array}$ & $\begin{array}{l}\text { ket } \\
\text { with a good select } \\
\text { with a good select }\end{array}$ & $\begin{array}{l}n \text { of fres } \\
n \text { of fres }\end{array}$ & $\begin{array}{l}\text { etables } \\
\text { processed (canne }\end{array}$ & ozen, \\
\hline
\end{tabular}

in the Brooklyn sample). The mean difference in combined fruit and vegetable intake may be explained by the instruments used to estimate intake. The present study used a two-item screener that separately asked each respondent to indicate the number of servings usually consumed each day of fruit or vegetables. The intake among Brooklyn seniors was estimated using the National Cancer Institute Fruit and Vegetable Screener, which separately asks the frequency over the last month and the amount consumed each time for $100 \%$ juice, fruit, lettuce salad, French fries or fried potatoes, other white potatoes, cooked dried beans, other vegetables, tomato sauce, vegetable soup, and other mixtures that include vegetables $[44,69]$. Separate questions on lettuce salads, French fried potatoes, tomato sauce, vegetable soups, and mixtures that included vegetables may be responsible for the larger estimated intake in the Brooklyn sample. Second, mean distance to the primary store for grocery purchase was much farther in this rural sample (14.8 miles vs. 0.8 miles). Finally, a higher percentage of rural seniors were married, a smaller percentage lived alone, and men comprised a larger proportion of the rural sample. The Brooklyn sample was recruited from 10 senior centers, where participants are more likely female or live alone [70]. In contrast, the present rural sample was randomly recruited through random-digit dialing and may better represent older adults in the rural areas. In addition, perceptions of community and household food resources, which were not included in the urban regression analyses, were consistently and negatively associated with fruit and vegetable intake. Others have also found that the perception of the community food environment influences the food chosen for the household [48,71]. Furthermore rural residents are more likely to believe they had restricted access to food resources, higher food costs, and poor quality and variety $[53,72]$.

Several additional findings warrant further mention: 1) the distance to the nearest food store with a good selection of fruit or vegetables decreased when fruit or vegetables included canned, frozen, and 100\% juice types in addition to fresh; 2) perception of fair or poor variety of fruit and vegetables in the store where most of the groceries were purchased was associated with decreased daily fruit intake (greater than one-quarter serving), but not vegetable intake; 3 ) perceptions there were few grocery stores or supermarkets in their community was associ- 
Table 6: Association of sample characteristics, community and household food resources, and network distance to fruit with combined fruit and vegetable intake among 582 rural seniors, using multivariable linear regression models

\begin{tabular}{|c|c|c|c|c|c|c|}
\hline & \multicolumn{2}{|c|}{ Model 1: Supermarket } & \multicolumn{2}{|c|}{ Model 2: Fresh Fruit } & \multicolumn{2}{|c|}{$\begin{array}{l}\text { Model 3: Fresh and } \\
\text { Processed Fruit }\end{array}$} \\
\hline & Coef (SE)a & $P$ & Coef (SE)a & $P$ & Coef (SE) ${ }^{a}$ & $P$ \\
\hline \multicolumn{7}{|l|}{ Individual characteristics } \\
\hline Live alone & $-0.544(0.150)$ & 0.000 & $-0.517(0.149)$ & 0.001 & $-0.539(0.149)$ & 0.000 \\
\hline Female & $0.494(0.138)$ & 0.000 & $0.521(0.138)$ & 0.000 & $0.491(0.138)$ & 0.000 \\
\hline Age, $y$ & $0.045(0.009)$ & 0.000 & $0.045(0.009)$ & 0.000 & $0.045(0.009)$ & 0.000 \\
\hline \multicolumn{7}{|l|}{ Food Resources } \\
\hline Food not last & $-0.968(0.182)$ & 0.000 & $-0.947(0.184)$ & 0.000 & $-0.945(0.182)$ & 0.000 \\
\hline Few grocery stores & $-0.299(0.132)$ & 0.024 & $-0.332(0.132)$ & 0.012 & $-0.341(0.131)$ & 0.010 \\
\hline Fruit/vegetable variety & $-0.399(0.197)$ & 0.043 & $-0.412(0.196)$ & 0.036 & $-0.407(0.193)$ & 0.036 \\
\hline \multicolumn{7}{|l|}{ Distance to nearest food store } \\
\hline Supermarket ${ }^{\mathrm{b}}$ & $-0.020(0.006)$ & 0.002 & & & & \\
\hline Fresh fruitc & & & $-0.017(0.012)$ & 0.153 & & \\
\hline Fresh and processed fruitd & & & & & $-0.043(0.015)$ & 0.005 \\
\hline $\mathrm{R}^{2}$ & 0.152 & & 0.142 & & 0.151 & \\
\hline$P$ & $<0.0001$ & & $<0.0001$ & & $<0.0001$ & \\
\hline $\begin{array}{l}\text { a SE }=\text { White-corrected standard } \\
\text { b Network distance in miles from } \\
\text { c Network distance in miles from } \\
\text { d Network distance in miles from } \\
\text { and } 100 \% \text { juice) fruit }\end{array}$ & $\begin{array}{l}\text { int's residence to } \\
\text { int's residence to ne } \\
\text { int's residence to ne }\end{array}$ & $\begin{array}{l}\text { est sup } \\
\text { est fooc } \\
\text { est foo }\end{array}$ & $\begin{array}{l}\text { ket } \\
\text { with a good select } \\
\text { with a good selec }\end{array}$ & of fre & Inroce & zen, \\
\hline
\end{tabular}

ated with decreased intake of vegetables and not fruit; 4) neighborhood socioeconomic deprivation and population density were not associated with fruit and vegetable intake; 5) negative perceptions of community food resources were consistently associated with decreased intake of combined fruit and vegetables; and 6) the magnitude of association with decreased intake of fruit, vegetables, and combined fruit and vegetables was largest for limited household food resources; that is, food purchased in the past month not lasting and no money available to purchase more food. Generally, studies have shown that neighborhood access to a supermarket influences individual fruit and vegetable consumption [8,33,73-77]. However, the results may be different when we consider neighborhood characteristics, such as socioeconomics, racial mix, or population density. Although our prior work found that high deprivation rural neighborhoods (CBG) had better relative potential access to a supermarket than other neighborhoods and neighborhoods of low population density had worse access [51], this study found no statistically significant relationship (unadjusted or adjusted) of either neighborhood deprivation or population density to fruit and vegetable intake. Our finding of no association between neighborhood deprivation and fruit and vegetable intake is similar to the findings in a couple of non-U.S. studies $[74,75]$ and dissimilar to a U.S. study using NHANES data [73]. Neither neighborhood socioeconomic deprivation nor population density was included in the recent study of NY seniors [44].

This study linked two contemporaneous datasets (BVFEP and BVHA) with the 2000 U.S. Census. The BVFEP food store data in this study were originally collected using ground-truthed methods that involved direct observation of all food stores and food service places in all six rural counties, on-site collection of locational points using mobile Global Positioning System, and on-site collection of presence of fresh, canned, frozen, and $100 \%$ juice fruit and vegetables. The ground-truthed method provided more accurate information than utilization of publicly available food stores lists [51]. This approach responded to methodological challenges that have been identified in measuring potential access to food stores in rural areas [78]. Considering that supermarkets and grocery stores are no longer the only shopping opportunities for fruit and vegetables, BVFEP data recognized the emergence of new and changing food 
Table 7: Association of sample characteristics, community and household food resources, and network distance to vegetables with combined fruit and vegetable intake among 582 rural seniors, using multivariable linear regression models

\begin{tabular}{|c|c|c|c|c|c|c|}
\hline & \multicolumn{2}{|c|}{ Model 1: Supermarket } & \multicolumn{2}{|c|}{ Model 2: Fresh Vegetables } & \multicolumn{2}{|c|}{$\begin{array}{c}\text { Model 3: Fresh and } \\
\text { Processed Vegetables }\end{array}$} \\
\hline & Coef (SE) $)^{a}$ & $P$ & Coef (SE) $)^{a}$ & $P$ & Coef (SE) $)^{a}$ & $P$ \\
\hline \multicolumn{7}{|l|}{ Individual characteristics } \\
\hline Live alone & $-0.544(0.150)$ & 0.000 & $-0.521(0.149)$ & 0.000 & $-0.549(0.149)$ & 0.000 \\
\hline Female & $0.494(0.138)$ & 0.000 & $0.518(0.138)$ & 0.000 & $0.494(0.138)$ & 0.000 \\
\hline Age, y & $0.045(0.009)$ & 0.000 & $0.044(0.009)$ & 0.000 & $0.043(0.009)$ & 0.000 \\
\hline \multicolumn{7}{|l|}{ Food Resources } \\
\hline Food not last & $-0.968(0.182)$ & 0.000 & $-0.950(0.184)$ & 0.000 & $-0.947(0.183)$ & 0.000 \\
\hline Few grocery stores & $-0.299(0.132)$ & 0.024 & $-0.340(0.131)$ & 0.010 & $-0.335(0.132)$ & 0.011 \\
\hline Fruit/vegetable variety & $-0.399(0.197)$ & 0.043 & $-0.416(0.197)$ & 0.035 & $-0.415(0.194)$ & 0.033 \\
\hline \multicolumn{7}{|l|}{ Distance to nearest food store } \\
\hline Supermarket ${ }^{\mathrm{b}}$ & $-0.020(0.006)$ & 0.002 & & & & \\
\hline Fresh vegetablec & & & $-0.021(0.011)$ & 0.054 & & \\
\hline Fresh and processed vegetabled & & & & & $-0.046(0.016)$ & 0.004 \\
\hline $\mathrm{R}^{2}$ & 0.152 & & 0.148 & & 0.152 & \\
\hline$P$ & $<0.0001$ & & $<0.0001$ & & $<0.0001$ & \\
\hline
\end{tabular}

a $\mathrm{SE}=$ White-corrected standard errors

${ }^{b}$ Network distance in miles from participant's residence to nearest supermarket

c Network distance in miles from participant's residence to nearest food store with a good selection of fresh vegetables

d Network distance in miles from participant's residence to nearest food store with a good selection of fresh and processed (canned, frozen,

and $100 \%$ juice) vegetables

store formats [65]. Not only was this study able to calculate the network distance from the residence of all rural seniors in the BVHA to the nearest supermarket, but also to the nearest food store offering a good selection of fresh fruit, fresh vegetables, fresh and processed fruit, or fresh and processed vegetables $[55,65]$.

This study has several limitations. Daily consumption of fruit and vegetables was estimated through a selfreported, self-administered two-item survey, which is subject to measurement error. Unlike the Brooklyn study, the identification of participant's primary grocery destination was not available [44]. As a result, our distance measures describe potential spatial access to the nearest locations. Although the respondents were representative of the population distribution geographically and persons with a household income below the poverty threshold, women were overrepresented and racial/ethnic minorities (African Americans and Hispanics) and individuals with limited education (completed less than $9^{\text {th }}$ grade) were underrepresented in the survey sample [62]. Another limitation is lack of data on social support. Additionally, the cross-sectional nature of the data prevents an examination of causality in fruit and vegetable intake. Confirmation of these findings in other rural senior populations is needed.

Despite these limitations, the data presented suggest that distance to the nearest supermarket or food store, regardless of type, with a good selection of fresh and processed fruit or vegetables was associated with daily consumption of fruit, vegetables, and combined fruit and vegetables. For rural seniors, increased distance to food stores was associated with decreased fruit and vegetable intake. Further, inadequate household food resources and perceptions of fair or poor community food resources were also associated with lower intake of fruit and vegetables among rural seniors. This is particularly important, given that there has been limited attention to environmental factors that may influence food choice and dietary intake among rural seniors. As important as easy access to community food sources are to a healthy diet, rural seniors are particularly disadvantaged. For rural seniors, many of whom have to watch their fixed income, the changing grocery store environment translates into a lack of choice in food store destination where they shop, lim- 
ited selection, and higher prices $[79,80]$. Having to shop outside the area where they live, rural seniors face challenges with private transportation or increased dependency on others [53].

\section{Conclusion}

Rural areas have reported disadvantages when it comes to availability, accessibility, and adequacy of health and social services and healthy foods, which particularly affects seniors $[57,81]$. This study goes beyond prior studies by examining access to food stores and availability and variety of fresh and processed fruit and vegetables by rural seniors. Seniors who reside in rural areas may be influenced to a large extent by the demands placed on individuals by adequacy of home, neighborhood, and community resources. Rural seniors' nutritional health may face greater challenges due to limited resources, difficulties with transportation, and greater distance to food resources. Indeed, many rural seniors who do not drive must rely on family, friends, and neighbors for transportation [81]. The findings of this study show that rural seniors consume few daily servings of fruit and vegetables. Rural seniors who live alone, have inadequate household and community food resources, or live a greater distance from the nearest supermarket or food store offering a good selection of fresh and processed fruit or vegetables are most at risk for low fruit and vegetable intake.

Thus, greater attention must be directed toward the availability and utilization of food resources in rural areas. To foster creative and effective community-based approaches to meeting dietary needs, prospective research needs to be conducted, which identifies the household, neighborhood, and community barriers and facilitators to healthful food choices. Additional research is needed to better understand older consumers and how characteristics of the home and community food environment in rural areas serve as barriers and facilitators for healthful eating. Interventions targeting the prevention and management of nutrition-related health conditions, especially for rural seniors, should understand the context in which rural seniors live and shop, and recognize the influence of access and availability to healthy food on an individual's ability to initiate and maintain a healthy nutritional lifestyle. Educational interventions need to emphasize the availability of healthy foods in non-conventional locations such as convenience and dollar stores. Furthermore, considering the importance of all vegetables and all fruits in this study, they should also focus on the beneficial nutritional characteristics of frozen and canned fruits and vegetables.

It is difficult to initiate or maintain healthful eating habits without access to healthful foods. Large numbers of an increasingly diverse older population are living in rural areas; many of whom face the burden of disease, increased economic constraints, and greater spatial inequality for access to healthful food. Indeed, the preparation for policy change to strengthen food assistance programs or program delivery activities, or interventions to improve nutritional health of this growing population should include an understanding of the community where people live and where they shop for food [82].

\section{Competing interests \\ The authors declare that they have no competing interests.}

\section{Authors' contributions}

JRS developed the original idea for the study. JRS wrote the first draft of the paper. JRS, CMJ, and WRD read and approved the final manuscript.

\section{Acknowledgements}

The analysis and drafting of the manuscript was supported by USDA RIDGE Program; National Center on Minority Health and Health Disparities grant \#5P20MD002295; and Centers for Disease Control and Prevention, Prevention Research Centers Program, through the Center for Community Health Development cooperative agreement \#1U48DP001924-01. The views are ours and do not represent those of the funders.

\section{Author Details}

1 Program for Research in Nutrition and Health Disparities, School of Rural Public Health, Texas A\&M Health Science Center, MS 1266, College Station, TX 77843-1266, USA and 2 Texas Healthy Aging Research Network (TxHAN) Collaborating Center, Center for Community Health Development, School of Rural Public Health, Texas A\&M Health Science Center, MS 1266, College Station, TX 77843-1266, USA

Received: 23 December 2009 Accepted: 2 June 2010 Published: 2 June 2010

\section{References}

1. Federal Interagency Forum on Aging-Related Statistics: Older Americans 2008: Key Indicators of Well-Being Washington, DC: U.S. Government Printing Office; 2008.

2. U.S. Department of Agriculture and U.S. Department of Health and Human Services (USDA/HHS): Dietary Guidelines for Americans 2005 Retrieved January 14, 2005. 2005 [http://www.health.gov/ dietaryguidelines/dga2005/document/pdf/DGA2005.pdf]

3. USDA Center for Nutrition Policy and Promotion (CNPP): MyPyramid. [http://www.mypyramid.gov/]. Retrieved March 24, 2008

4. Hu FB, Manson JE, Stampfer MJ, Colditz G, Liu S, Solomon CG, Willett WC: Diet, lifestyle, and the risk of type 2 diabetes mellitus in women. $\mathrm{NEngl}$ J Med 2001, 345(11):790-797.

5. Ness AR, Powles JW: Fruit and vegetables, and cardiovascular disease: a review. Int J Epidemiol 1997, 26:1-13.

6. Steinmetz KA, Potter JD: Vegetables, fruit, and cancer prevention: a review. J Am Diet Assoc 1996, 96:1027-1039.

7. VanDuyn MA, Pivonka E: Overview of the health benefits of fruit and vegetable consumption for the dietetics professional: selected literature. J Am Diet Assoc 2000, 100:1511-1521.

8. Morland K, Wing S, Roux AD: The Contextual Effect of the Local Food Environment on Residents' Diets: The Atherosclerosis Risk in Communities Study. Am J Public Health 2002, 92(11):1761-1767.

9. Rose D, Richards R: Food store access and household fruit and vegetable use among participants in the US Food Stamp Program. Public Health Nutrition 2004, 7(8):1081-1088.

10. Caldwell EM, Kobayashi MM, DuBow WM, Wytinck SM: Perceived access to fruits and vegetables associated with increased consumption. Public Health Nutrition 2009, 12(10):1743-50.

11. Robinson T: Applying the Socio-ecological Model to Improving Fruit and Vegetable Intake Among Low-Income African Americans. J Community Health 2008, 33:395-406.

12. Diez-Roux AV, Nieto FJ, Caulfied L, Tyroler HA, Watson RL, Szklo M: Neighbourhood differences in diet: the Atherosclerosis Risk in 
Communities (ARIC) Study. J Epidemiol Community Health 1999, 53:55-63.

13. Zenk SN, Lachance LL, Schulz AJ, Mentz G, Kannan S, Ridella W: Neighborhood Retail Food Environment and Fruit and Vegetable Intake in a Multiethnic Urban Population. American Journal of Health Promotion 2009, 23:255-64.

14. Winkler $\mathrm{E}$, Turrell $\mathrm{G}$, Patterson C: Does living in a disadvantaged area mean fewer opportunities to purchase fresh fruit and vegetables in the area? Findings from the Brisbane food study. Health \& Place 2006, 12:741-8.

15. Franco M, Roux AVD, Glass TA, Caballero B, Brancati FL: Neighborhood Characteristics and Availability of Healthy Foods in Baltimore. Am J Prev Med 2008, 35:561-7.

16. Hosler A, Rajulu DT, Frederick BL, Ronsani AE: Assessing Retail Fruit and Vegetable Availability in urban and Rural Underserved Communities. Prev Chronic Dis 2008, 5(4):A123.

17. Algert SJ, Agrawal A, Lewis DS: Disparities in Access to Fresh Produce in Low-Income Neighborhoods in Los Angeles. Am J Prev Med 2006, 30:365-70.

18. Rickman JC, Barrett DM, Bruhn CM: Nutritional comparison of fresh, frozen and canned fruits and vegetables. Part 1. Vitamins $C$ and $B$ and phenolic compounds. J Sci Food Agric 2007, 87:930-44.

19. Booth SL, Sallis JF, Ritenbaugh C, Hill JO, Birch LL, Frank LD, Glanz K, Himmelgreen DA, Mudd M, Popkin BM, Rickard KA, St. Jeor S, Hays NP: Environmental and Societal Factors Affect Food Choice and Physical Activity: Rationale, Influences, and Leverage Points. Nutr Rev 2001, 59(3):S21-S39.

20. Casey AA, Elliott M, Glanz K, Haire-Joshu D, Lovegreen SL, Saelens BE, Sallis JF, Brownson RC: Impact of the food environment and physical activity environment on behaviors and weight status in rural U.S. communities. Preventive Medicine 2008, 47:600-604.

21. Baker $A H$, Wardle J: Sex differences in fruit and vegetable intake in older adults. Appetite 2003, 40(3):269-275.

22. Locher JL, Sharkey JR: An Ecological Perspective on Older Adult Eating Behavior. In Handbook of Clinical Nutrition and Aging 2 nd edition. Edited by: Bales CW, Ritchie CS. New York: Humana Press; 2009:3-16.

23. Vitolins MZ, Tooze JA, Golden SL, Arcury TA, Bell RA, Davis C, DeVellis RF, Quandt SA: Older Adults in the Rural South Are Not Meeting Healthful Eating Guidelines. J Am Diet Assoc 2007, 107:265-272.

24. Kearney M, Kearney JM, Dunne A, Gibney MJ: Sociodemographic determinants of perceived influences on food choice in a nationally representative sample of Irish adults. Public Health Nutrition 2000, 3(2):219-226

25. Turrell G, Hewitt B, Patterson C, Oldenburg B, Gould T: Socioeconomic differences in food purchasing behaviour and suggested implications for diet-related health promotion. J Hum Nutr Dietet 2002, 15:355-364.

26. Watters JL, Satia JA, Galanko JA: Associations of psychosocial factors with fruit and vegetable intake among African-Americans. Public Health Nutrition 2007, 10(7):701-711.

27. French SA, Story M, Jeffery RW: Environmental Influences on Eating and Physical Activity. Annu Rev Public Health 2001, 22:309-335.

28. Horowitz CR, Colson KA, Hebert PL, Lancaster K: Barriers to Buying Healthy Foods for People With Diabetes: Evidence of Environmental Disparities. Am J Public Health 2004, 94(9):1549-1554.

29. Kamphuis CB, Giskes K, de Bruijn GJ, Wendel-Vos W, Brug J, van Lenthe FJ: Environmental determinants of fruit and vegetable consumption among adults: a systematic review. Br J Nutr 2006, 96:620-635.

30. Laraia BA, Siega-Riz AM, Kaufman JS, Jones SJ: Proximity of supermarkets is positively associated with diet quality index for pregnancy. Preventive Medicine 2004, 39:869-875.

31. Moore LV, Roux AVD, Brines S: Comparing Perception-Based and Geographic Information System (GIS-Based Characterizations of the Local Food Environment. Journal of Urban Health 2008, 85(2):206-216.

32. Block D, Kouba J: A comparison of the availability and affordability of a market basket in two communities in the Chicago area. Public Health Nutrition 2006, 9(7):837-845.

33. Bodor JN, Rose D, Farley TA, Swalm C, Scott SK: Neighbourhood fruit and vegetable availability and consumption: the role of small food stores in an urban environment. Public Health Nutrition 2007, 11(4):413-420.

34. Chung C, Myers SL: Do the Poor Pay More for Food? An Analysis of Grocery Store Availability and Food Price Disparities. The Journal of Consumer Affairs 1999, 33(2):276-296.
35. Morland $\mathrm{K}$, Filomena S: Disparities in the availability of fruits and vegetables between racially segregated urban neighborhoods. Public Health Nutrition 2007, 10(12):1481-1489.

36. Zenk SN, Schulz AJ, Israel BA, James SA, Bao S, Wilson ML: Neighborhood Racial Composition, Neighborhood Poverty, and the Spatial Accessibility of Supermarkets in Metropolitan Detroit. Am J Public Health 2005, 95:660-667.

37. Apparicio P, Cloutier MS, Shearmur R: The case of Montreal's missing food deserts: Evaluation of accessibility to food supermarkets. Int $\mathrm{J}$ Health Geogr 2007, 6:4

38. Burns CM, Inglis AD: Measuring food access in Melbourne: Access to healthy and fast foods by car, bus and foot in an urban municipality in Melbourne. Health \& Place 2007, 13:877-885.

39. Clarke G, Eyre H, Guy C: Deriving Indicators of Access to Food Retail Provision in British Cities: Studies of Cardiff, Leeds and Bradford. Urban Studies 2002, 39(11):2041-2060.

40. Larsen K, Gilliland J: Mapping the evolution of 'food deserts' in a Canadian city: Supermarket accessibility in London, Ontario, 19612005. International Journal of Health Geographics 2008, 7:

41. Latham J, Moffat T: Determinants of variation in food cost and availability in two socioeconomically contrasting neighborhoods of Hamilton, Ontario, Canada. Health \& Place 2007, 13(1):273-287.

42. Pearce J, Day P, Witten K: Neighbourhood Provision of Food and Alcohol Retailing and Social Deprivation in Urban New Zealand. Urban Policy and Research 2008, 26(2):213-227.

43. Smoyer-Tomic KE, Spence JC, Amrhein C: Food Deserts in the Prairies? supermarket Accessibility and Neighborhood Need in Edmonton, Canada. The Professional Geographer 2006, 58(3):307-326.

44. Morland K, Filomena S: The utilization of local food environments by urban seniors. Prev Med 2008, 47(3):289-293.

45. Smith GC: Grocery Shopping Patterns of the Ambulatory Urban Elderly. Environment and Behavior 1991, 23(1):86-114.

46. Wilson LC, Alexander A, Lumbers M: Food access and diet variety among older people. International Journal of Retail \& Distribution Management 2004, 32(2):109-122.

47. Blanchard T, Lyson T: Food Availability \& Food Deserts in the Nonmetropolitan South Retrieved August 5, 2007. 2006 [http:// srdc.msstate.edu/focusareas/health/fa/fa 12 blanchard.pdf].

48. Jilcott SB, Laraia BA, Evenson KR, Ammerman AS: Perceptions of the Community Food Environment and Related Influences on Food Choice Among Midlife Women Residing in Rural and urban Areas: A Qualitative Analysis. Women \& Health 2009, 49:164-180.

49. Kaufman PR: Rural Poor Have Less Access to Supermarkets, Large grocery Stores. Rural Development Perspectives 1998, 13(3):19-26.

50. Liese AD, Weis KE, Pluto D: Food store types, availability and cost of foods in a rural environment. J Am Diet Assoc 2007, 107:1916-1923.

51. Sharkey J, Horel S: Neighborhood Socioeconomic Deprivation and Minority Composition Are Associated with Better Potential Spatial Access to the Food Environment in a Large Rural Area. J Nutr 2008, 138:620-627.

52. Sharkey JR, Horel S, Han D, Huber JC: Association between Neighborhood Need and Spatial Access to Food Stores and Fast Food Restaurants in Neighborhoods of Colonias. Int J Health Geogr 2009, 8:9

53. Smith C, Morton LW: Rural Food Deserts: Low-income Perspectives on Food Access in Minnesota and lowa. J Nutr Educ Behav 2009, 41:176-187.

54. Clifton KJ: Mobility Strategies and Food Shopping for Low-Income Families. Journal of Planning Education and Research 2004, 23:402-413.

55. Bustillos BD, Sharkey JR, Anding J, McIntosh A: Availability of healthier food alternatives in traditional, convenience, and non-traditional types of food stores in two rural Texas counties. J Am Diet Assoc 2009, 109(5):883-889.

56. Larson NI, Story MT, Nelson MC: Neighborhood Environments: Disparities to Access to Healthy Foods in the U.S. Am J Prev Med 2009, 36(1):74-81.

57. Morton LW, Blanchard TC: Starved for Access: Life in Rural America's Food Deserts. Rural Realities 2007, 1(4):1-10.

58. Powell LM, Slater S, Mirtcheva D, Bao Y, Chaloupka FJ: Food store availability and neighborhood characteristics in the United States. Preventive Medicine 2007, 44:189-195.

59. U.S. Census Bureau: State and County QuickFacts. [http:// quickfacts.census.gov/afd/states/48/48215.html]. Retrieved February 18 , 2007 
60. Brazos Transit: Brazos Transit District Retrieved 8/10/2007. [http:// www.btd.org/]

61. Brazos Valley Council of Governments (BV COG): "Here to There" Coordinated Regional Public Transportation Plan Brazos Valley Region, Texas; 2006

62. Sharkey JR, Horel S, Johnson CM, Rodolfo M, Nayga J: Understanding Nutritional Challenges Faced by Older Americans in Rural Areas: the Role of the Food Environment and Neighborhood Characteristics Report to the USDA RIDGE program; 2009 .

63. Resnicow K, Odom E, Wang T, Dudley W, Mitchell D, Vaughan R, Jackson A, Baranowski T: Validation of three food frequency questionnaires and 24-hour recalls with serum carotenoid levels in a sample of African American adults. Am J Epidemiol 2000, 152:1072-80.

64. Campbell M, Carr C, DeVellis B, Switzer B, Biddle A, Amamoo M, Walsh J, Zhou B, Sandler R: A randomized trial of tailoring and motivational interviewing to promote fruit and vegetable consumption for cancer prevention and control. Ann Behav Med 2009, 38:71-85.

65. Sharkey JR, Horel S, Dean WR: Neighborhood Deprivation, vehicle Ownership, and Potential Spatial Access to a Variety of Fruits and Vegetables in a Large Rural Area in Texas. Int J Health Geogr 2010, 9:26.

66. Bazzano LA: The High Cost of Not Consuming Fruits and Vegetables. $J$ Am Diet Assoc 2006, 106(9):1364-1368.

67. Joshipura KJ, Hu FB, Manson JE, Stampfer MJ, Rimm EB, Speizer FE, Colditz G, Ascherio A, Rosner B, Spiegelman D, Willett WC: The effect of fruit and vegetable intake on risk for coronary heart disease. Ann Intern Med 2001, 134(12):1106-1114.

68. Serdula MK, Byers T, Mokdad AH, Simoes E, Mendlein JM, Coates RJ: The association between fruit and vegetable intake and chronic disease risk factors. Epidemiology 1996, 7(2):161-165.

69. Subar A, Thompson F, Kipnis V, Midthune D, Hurwitz P, McNutt S, McIntosh A, Rosenfeld S: Comparative Evaluation of the Block, Willett, and National Cancer Institute Food Frequency Questionnaires: The Eating at America's Table Study. Am J Epidemiol 2001, 154:1059-99.

70. Ponza M, Ohls JC, Millen BE: Serving Elders at Risk: The Older Americans Act Nutrition Programs, National Evaluation of the Elderly Nutrition Program, 1993-1995. Princeton, NJ: Mathematica Policy Research, Inc; 1996.

71. Inglis V, Ball K, Crawford D: Socioeconomic variations in women's diets: what is the role of perceptions of the local food environment? J Epidemiol Community Health 2008, 62:191-197.

72. Garasky S, Morton LW, Greder K: The Food Environment and Food Insecurity: Perceptions of Rural, Suburban, and Urban Food Pantry Clients in lowa. Family Economics and Nutrition Review 2004, 16(2):41-48.

73. Dubowitz T, Heron M, Bird CE, Lurie N, Finch BK, Basurto-Davilá R, Hale L, Escarce JJ: Neighborhood socioeconomic status and fruit and vegetable intake among whites, blacks, and Mexican Americans in the United States. Am J Clin Nutr 2008, 87:1883-1891.

74. Pearce J, Hiscock R, Blakely T, Witten K: The contextual effects of neighbourhood access to supermarkets and convenience stores on individual fruit and vegetable consumption. J Epidemiol Community Health 2008, 62:198-201

75. Pearson T, Russell J, Campbell MJ, Barker ME: Do 'food deserts' influence fruit and vegetable consumption? - a cross-sectional study. Appetite 2005, 45:195-197.

76. Zenk SN, Schulz AJ, Hollis-Neely T, Campbell RT, Holmes N, Watkins G, Nwankwo R, Odoms-Young A: Fruit and Vegetable Intake in African Americans: Income and Store Characteristics. Am J Prev Med 2005, 29(1):1-9.

77. Zenk SN, Schulz AJ, Israel BA, James SA, Bao S, Wilson ML: Fruit and Vegetable Access Differs by Community Racial Composition and Socioeconomic Position in Detroit, Michigan. Ethn Dis 2006, 16:275-280

78. Sharkey JR: Measuring Potential Access to Food Stores and Food Service Places in Rural Areas in the United States. Am J Prev Med 2009, 36(4S):S151-S155.

79. Falk LW, Bisogni CA, Sobal J: Food Choice Processes of Older Adults: A Qualitative Investigation. JNE 1996, 28:257-265.

80. Kelly FM, Parker AJ: A Study of Retail Accessibility for Older People Dublin: The Centre for Retail Studies, University College; 2005.

81. Krout JA, Bull CN: Service Delivery to Rural Elders: Barriers and Challenges. In Service Delivery to Rural Older Adults: Research, Policy, and
Practice Edited by: Goins RT, Krout JA. New York: Springer Publishing Company; 2006:21-36.

82. Gesler WM, Hayes M, Arcury TA, Skelly AH, Nash S, Soward AC: Use of mapping technology in health intervention research. Nurs Outlook 2004, 52:142-146

\section{Pre-publication history}

The pre-publication history for this paper can be accessed here: http://www.biomedcentral.com/1471-2318/10/32/prepub

doi: 10.1186/1471-2318-10-32

Cite this article as: Sharkey et al., Food Access and Perceptions of the Community and Household Food Environment as Correlates of Fruit and Vegetable Intake among Rural Seniors BMC Geriatrics 2010, 10:32

\section{Submit your next manuscript to BioMed Centra and take full advantage of:}

- Convenient online submission

- Thorough peer review

- No space constraints or color figure charges

- Immediate publication on acceptance

- Inclusion in PubMed, CAS, Scopus and Google Scholar

- Research which is freely available for redistribution

Submit your manuscript at www.biomedcentral.com/submit
C Biomed Central 